Aus der k. k. II. chirurgischen Universitätsklinik zu Wien (Vorstand: Hofrat Prof. I)r. J. Hochenegg).

\title{
Über das Wesen der sogenannten retrograden Inkarzeration des Darmes ').
}

Von Privatdozent Dr. Hans Lorenz, Assistenten der Klinik.

(Mit 11 Abbildungen.)

Es ist ein eigentümlicher Befund, für den - unter anderen Namen - die Bezejchnung "retrograde Inkarzeration des Darmes“ geprägt wurde. Bei der Herniotomie einer irreponiblen, als inkarzeriert angesprochenen Hernie trifft man im Bruchsack zwei Darmschlingen nebeneinander, die gar keine nennenswerten oder nur mittelschwere Veränderungen zeigen, während das im Bauche gelegene, die beiden "Bruchdarmschlingen" verbindende Darmstück - die "Verbindungsschlinge“ - schwere, nicht selten nach wenigen Stunden schon irreparable Ernährungsstörungen aufweist.

Im Jahre 1880 hat Benno Schmĩdt $\left.(26)^{2}\right)$ den ersten einschlägigen Fall in der Literatur niedergelegt, ohne damit in weiteren Kreisen Beachtung zu finden.

Noch schlimmer erging es Hochenegg(5) mit seinem 1857 beobachteten, 1889 an allerdings verstecktem Orte veröffentlichten Fall: seine Beobachtung wurde von allen späteren Bearbeitern des interessanten Themas übersehen.

Auf dem Chirurgenkongrels 1894 machte dann Lauenstein (13), ohne Kenntnis der beiden vor ihm publizierten Fälle, den Versuch, die Aufmerksamkeit auf die in Rede stehende Bruchform zu lenken. Aber auch seine Mitteilungen fanden anfangs nur wenig Beachtung und sind selbst Maydl(21) entgangen, als dieser im $J_{\text {iahr darauf }}$ durch seine anfsehenerregenden Befunde an Tube und Wurmfortsatz den Begriff der retrograden Inkarzeration schuf. I)as Wesen dieser Einklemmungsart besteht nach Maydl darin, daß ,der inkarzerierte

1) Von der Redaktion übernommen Juli 1909.

2) Diese Zahlen beziehen sich auf das am Schlusse dieser Arbeit angefügte Literaturverzeichnis. 
Über das Wesen der sogenannten retrograden Inkarzeration des Darmes. 57

Teil des Organs bauchwärts vom Inkarzerationsringe gelegen ist, während peripherwärts von ihm, $d . h$. im Bruchsack selbst, sich ein verhältnismäßig normal beschaffener Teil des Eingeweides befindet".

Maydl kam schon damals auf die Möglichkeit einer „retrograden Inkarzeration" des Darms zu sprechen und konstruierte auf Grund theoretischer Überlegungen als allenfalls denkbar ein Bild, wie es tatsächlich schon von Schmidt, Hochenegg und Lauenstein angetroffen worden war. Er schrieb: "Wenn wir unter den Bancheingeweiden diejenigen bezeichnen wollten, welche einer retrograden Inkarzeration fähig sind, so wären der Darm, besonders der Dünndarm und die bewegliche Partie des Dickdarms, die gewöhnlich in Bruchsäcken gefunden werden, gewiß die letzten, an denen sich die erwähnte Erscheinung abspielen könnte.

Ich könnte mir diesen Vorgang nur so vorstellen, daß entweder eine vorgefallene Darmschlinge durch irgendwelche Kräfte, z. B. Taxisversuche, auf die Mesenterialfläche umgebogen und das konvexe Ende der Schlinge in die Bauchhöhle hineingepreßt würde, während der größte Teil der Schlinge im Bruchsack zurückbliebe.

Oder aber es könnte einmal eine bewegliche Darmschlinge mit ilirem konvexen Rand in der Umgebung des inneren Leistenringes fixiert werden und es könnte vorkommen, daß der zentral und peripher von dieser Stelle gelegene Teil des Darms in einen Bruchsack hinausgeprelit würde, so daß die außerhalb der Bauchhöhle befindliche Darmschlinge die Gestalt eines W hätte ${ }^{1}$ ), dessen mittlerer 'Teil sich eben innerhalb der Bauchhöhle fixiert befände. Sollte demnach in einem dieser Fälle eine retrograde Inkarzeration eintreten, so wäre es notwendig, daß die Bruchpforte eine solche Weite besäße, daß sie Raum böte für ein vielmaliges Hindurchtreten des Darms samt seinem Mesenterium. Solche Bruchpforten aber sehen wir nur ausnahmsweise und eben bei diesen können gerade wegen der Geräumigkeit der Bruchpforte Inkarzerationen fast nie beobachtet werden."

Die der ersten Publikation Maydls folgenden Jahre brachten so manche Mitteilung über retrograde Inkarzerationen des Appendix, der Tube, des Netzes, subseröser Tumoren, also verschiedener gestielter intraabdomineller Gebilde; man lernte die retrograde Inkarzeration des Wurmfortsatzes von dem inkarzerierten Appendix-

1) Auf diesen Vergleich stützt sich die später von de Beule gebrauchte Bezeichnung „Hernie en W“. 
Schlingenbruch Roses trennen und die Kenntnis der verschiedenen Ursachen beider Zustände wurden Allgemeingut der operativ tätigen Ärzte, - von einer retrograden Inkarzeration hingegen des Darmes selbst hörte man nichts mehr, bis 1902 v. Wistinghausen (30), anknüpfend an eine eigene Beobachtung des merkwürdigen Befundes, seine Ansichten über dessen Zustandekommen bekannt gab.

Nun folgte 1903 Langer(11), 1905 Lauenstein(14) mit drei neuen Beobachtungen. 1906 Pólya(23), Haim(2), Klauber(9), Pringle (25). Das Jahr 1907 brachte eine Polemik zwischen Kla uber und Lauenstein $(10,15,16)$ über das zur Streitfrage gewordene Thema, ferver Publikationen von Pólya(24), Jäckh(6), Jenckel (7,8), Manninger (20), Laroyenne(12) und Sultan(28), das verflossene Jahr die kritische Studie de Beules(1), die Publikationen von Heller $(3,4)$, Neumann (22), Takayasu(29), so dals heute gegen 30 Publikationen über den hochinteressanten Stoff vorliegen.

Doch wie überall hat sich auch hier das alte Sprichwort „viel Köpf', viel Sinn'" bewahrheitet und wir sind hente kaum weiter als vor zwei Jabren, da Lauenstein in seiner dritten Publikation zu dem Thema(15) schrieb: „an dieser Brucheinklemmung sei noch so manches unklar, daß es wohl nur allmählich durch weitere aufmerksame Beobachtung gelingen wird, die schwebenden Fragen zu beantworten."

Über eigene Beobachtungen verfügend, darf ich daher anch für mich das Wort erbitten.

Ich tue dies um so lieber, als ich das Thema schon früher einmal gestreift(19) und mich damals den Ansichten Klaubers und Haims angeschlossen habe, die ich heute nicht mehr für allgemein gültig ansehen kann.

Ehe ich an die kritische Besprechung der in der Literatur niedergelegten und an die Mitteilung meiner eigenen Fälle schreite, möchte ich noch hervorheben, daß nicht das Auffinden zweier Darmschlingen in einem eingeklemmten Bruch es ist, was unser Interesse so besonders erregt; denn warum sollten bei genügend weiter Bruchpforte und genügend langem Mesenterium nicht gleichzeitig oder nacheinander zwei benachbarte Darmschlingen vorfallen und sich inkarzerieren können? ${ }^{\text {) }}$

1) Einer derartigen Inkarzeration zweier Darmschlingen müssen ja die mehrfach schon in der älteren Hernienliteratur gebrachten Befunde eines „Anus praeternaturalis mit 4 Öffnungen" nach spontanem Ablauf der Inkarzeration ihre Entstehung verdanken. 
Über das Wesen der sogenannten retrograden Inkarzeration des Darmes. 59

Das, was unsere Aufmerksamkeit erregt, ist die Ernährungsstörung des die beiden Bruchdarmschlingen verbindenden, intraabdominellen Darmstücks, das in seiner Ernährung mindestens so schwer, meist aber viel schwerer geschädigt ist, als die Bruchdarmschlingen.

Von diesem Standpunkte aus muß ich v. Wistinghausens zweiten Fall (30), die drei Fälle von Pringle(25) und die beiden Fälle Pólyas $(23,24)$ ausscheiden, so daß ich aus der Literatur bloß 22 für die Beurteilung der Frage zu verwertende Beobachtungen 1) beibringen kann, denen ich unten drei eigene anfüge ${ }^{2}$ ).

Wodurch leidet nun gerade die Verbindungsschlinge in ihrer Ernährung?

Die Beantwortung dieser Frage stößt auf große Schwierigkeiten, sie ist es, welche das Thema zu einer chirurgischen Streitfrage gemacht hat.

Schmidt(26) nahm an, daß ein den Okklusionssymptomen voraufgegangener Sturz seiner Patientin die eigentiumliche Lagerung der Darmschlingen verursacht habe und daß es im Gefolge davon zu einer Abschnürung der Mesenterialgefäße gekommen sei, dadurch, "daß die Darmschlinge (Verbindungsschlinge) nach ihrem Austritt aus der Bruchpforte (d. h. Wiedereintritt in die Bauchhöhle) seitlich abgeknickt und an der Innenfläche der Bauchwand angelagert war."

Hochenegg(5) war der Ansicht, daß es sich in seinem Falle um das Resultat von Taxisversuchen, um eine inkomplette Reposition der inkarzerierten Schlinge gehandelt habe und auch Maydl(21) - seine Worte habe ich schon oben zitiert - hielt das Entstehen des in Rede stehenden Befundes durch Taxisversuche für möglich.

Diese Deutung stößt aber auf schwere Bedenken; wo die Taxis gelingt, werden ja gerade die dem inkarzerierenden Ringe zunächst liegenden Partien der inkarzerierten Schlinge mobil gemacht und in den Bauchraum zurückgebracht; damit wird die Inkarzeration behoben und nun erst der übrige Bruchinhalt beweglich und reponibel. Wie sollte es gelingen, bei nicht behobener Inkarzeration gerade die periphersten Partien der inkarzerierten Schlinge, die in ihrer Ernährung am stärksten gelitten haben und am vulnerabelsten

1) Da zähle ich noch den aus anderen Gründen nicht ganz reinen Fall Sultans (23) mit, der unten noch zur Ausscheidung gelangen wird.

2) Während der Drucklegung dieser Arbeit hat dann noch La enstein (18) drei neue, eigene Fälle und einen Fall Enderlens mitgeteilt. 
sind, von ihrer vorgeschobenen Position wegzubringen und durch den Bruchring in den Bauchraum hinaufzuschieben?

Ein anderes Argument gegen diese Auffassung hat Lauenstein(14) beigebracht, der es mit Recht für unmöglich erklärt, ,daß nach erfolgter Einklemmung der einen Schlinge noch so viel Raum innerhalb des Einschnürungsringes bestehen bleibt, daß eine Darmschlinge von außen nach innen hindurchgetrieben werden könnte."

Man hat ferner in ihrer Ernährung schwer geschädigte Verbindungsschlingen gefunden von solcher Länge, daß sie in dem vorhandenen Bruchsack, zum mindesten gemeinsam mit den Bruchdarmschlingen, gar nicht Platz gehabt hätten.

Dies letztere Argument kann man auch der Deutung J encke $\mathbf{~ s ~}(7,8)$ entgegenhalten, der 1907 die Hypothese aufstellte, es handle sich bei der "retrograden Inkarzeration des Darms" um „Artefakte, durch brüske Taxisversuche hervorgerufen. Die erste Inkarzeration einer einzigen Schlinge wird dabei behoben, durch Stopfen und Kneten die malträtierte Schlinge mit ihrer Kuppe durch die relativ weite Bruchpforte in die Batchhöhle gepreßt, während von beiden Seiten, besonders vom aboralen 'T'eil, Darm in den Bruchsack nachgezogen wird. So kann es kommen, daßs innerhalb des Bruchsackes wenig veränderte Schlingen liegen, während die ursprünglich im Bruch gelegene, veränderte mittlere Partie in die freie Bauchhöhle mehr oder weniger lang hineinragt und dort die Symptome innerer Einklemmung verursacht."

Diese Theorie hätte zur Voraussetzung, daß die Taxis noch zn einer Zeit gelungen wäre, da die inkarzerierte Schlinge schon gangränös war oder wenigstens unmittelbar vor der ausgesprochenen Gangrän stand, also hämorrhagisch infarciert, plump und starr war.

Selbst die Möglichkeit einer Reduktion in diesem Stadium zugegeben, wäre es doch sehr merkwürdig, daß die plumpe, starre Schlinge, die vor der Taxis ihre Konvexität nach abwärts gekehrt hatte, dieselbe nach der Taxis nach oben kehren sollte, während die Fußpunkte der Verbindungsschlinge nach wie vor in der Höhe der Bruchpforte liegen blieben. Denn nur unter dieser Annalıme ließe sich der regelmäßige Befund erklären, daß die Ernährungsstörung der Verbindungsschlinge bis an die Bruchpforte heranreicht.

Fs ließen sich ohne große Schwierigkeit noch andere Gegengründe beibringen, doch unterlasse ich dies, weil ich glaube, daß schon die gemachten Finwände genïgen, meine ablehnende Haltung 
gegen Jenckels Theorie zu rechtfertigen. Sie hat auch bisher wenig Anhänger gefunden.

Ebensowenig kann ich Neumanns Ansicht(22) als befriedigende Erklärung akzeptieren. Er meint, daßs zunächst, bei stark nach vorn gebeugten Körper, alle drei Schlingen, also anch die spätere Verbindungsschlinge in den Bruchsack austräten, daß aber dann beim Lagewechsel, „beim Übergang in die Rückenlage der mittlere Teil der Schlinge mit dem relativ kurzen Mesenterium in die Bauchliöhle soweit zurückgerissen werde, als es einerseits der Zug nach der Radix mesenterii verlangte, andererseits die an dem Bauchring zurückgehaltenen Außenschlingen erlaubten. Durch diesen Zug und Gegenzug würden dann die Fußpunkte der Verbindungsschlinge und die Umschlagstelle des Mesenterium daselbst in solche Spannung versetzt, dals eine Verlegung und Thrombosierung der Gefäße und somit die Gangrän der Verbindungsschlinge die Folge sei". Diese Hypothese scheint mir schon deshalb hinfällig, weil das Mesenterium der Verbindungsschlinge keineswegs "relativ kurz" ist. In meinem im Anhang mitgeteilten Fall betrug beispielsweise seine Lü̈nge $35 \mathrm{~cm}$.

Die größte innere Wahrscheinlichkeit hat a priori die Annahme, daß die großen, im Mesenterium der Verbindungsschlinge verlaufenden, ihre Ernährung vermittelnden Gefäßße in ihrem Verlauf eine Unterbrechung erleiden, so wie es bei einer Strangulation im Innern der Bauchhöhle oder einer einfachen Brucheinklemmung der Fall ist.

Wodurch aber sollte die Unterbrechung der Blutzirkulation zustande kommen?

In Lauensteins erstem Fall fand sich eine $50 \mathrm{~cm}$ lange Verbindungsschlinge, die ganz dasselbe infarcierte Aussehen bot, wie die beiden im Bruchsack liegenden Schlingen, obwohl „ihr Mesenterium nicht mit abgeschnürt war, jedenfalls aber zentralwärts von dem umschnïrenden inneren Leistenringe lag" und somit als unter günstigeren Ernährungsbedingungen stehend zll betrachten war. Dieser Ansicht blieb Lauenstein anch tren, nachdem er drei weitere Fälle beobachtet hatte. Damals schrieb er(14): „Für die beiden äußeren Schlingen muß die Inkarzeration annähernd gleiche Zustände schaffen. Den topographisch-anatomischen Verhältnissen nach muß die innere Schlinge unter anderen Bedingungen stehen. Die Ursache hiefür liegt darin, daß nur die Mesenterialabschnitte der beiden änßeren Darmschlingen zwischen Radix mesenterii und Darminsertion abgeschnürt werden, während das bei der inneren Schlinge nicht der Fall ist. An ihr werden vielmehr nur die beiden 
Darmlumina abgeschnürt, aber nicht das Mesenterium, das innerhalb der Bauchhöhle frei von der Radix bis zum Einschnürungsring herab verläuft...... Danach müßte man annehmen, daß eigentlich bei der Inkarzeration die innere Darmschlinge unter wesentlich günstigeren Ernährungsverhältnissen stehen müsse als die änßeren Schlingen. Es bleibt daher um so unverständlicher, weshalb in Fall 3 es zu einer so schweren Ernährungsstörung der Darmwand kommen konnte."

Demgegenüber nahm Klauber(9) für seinen Fall an, daß das Mesenterium der Verbindungsschlinge die Bruchpforte zweimal passiert habe, daß dasselbe somit abgeklemmt, ja doppelt abgeklemmt war und daß dadurch die schwere Ernährungsstörung gerade der Verbindungsschlinge ungezwungen ihre vollkommene Aufklärung finde.

Haim (2), der bald darauf einen einschlägigen Fall operierte, schloß sich Klaubers Erklärung an und hob noch besonders hervor, daß seiner Meinung nach eine Inkarzeration der beiden Darmschlingen ursprünglich überhaupt nicht stattfinde; Beweis dessen, daß sie in seinem Fall unverändert waren; offenbar finde in diesen Fällen nur eine Einklemmung bzw. Strangulation der Verbindungsschlinge statt; in der Folge könne es dann durch Schwellung des durch die Bruchpforte ziehenden Mesenteriums zu einer Kompression der beiden Schlingen im Bruchsack und zur Bildung von Inkarzerationsringen kommen.

Jäckh (6), der die Kasuistik um zwei weitere Fälle bereicherte, teilte die Anschauungen von Klauber und Haim und auch mir schien diese Auffassung äußerst plausibel, als ich bald darauf den einzig dastehenden Operationsbefund einer reinen Inkarzeration des Dünndarmgekröses veröffentlichte (19), die zu schwerer Ernährungsstörung des zugehörigen Darmsegments geführt hatte.

La uenstein(15) bekämpfte die Erklärungsversuche von Klauber, Haim und Jäckh. Für ihn stand fest, daß in allen ihren Fällen „die Mesenterialgefälße der Verbindungsschlinge in ihrem Verlauf von der Radix mesenterii bis zum Darm hin überhaupt nicht eingeschnürt waren und daß die beobachteten Ernährungsstörungen der Verbindungsschlinge, die hämorrhagische Infarcierung, die Blutungen und Thrombosen des zugehörigen Mesenteriums auf andere Ursachen zurückzuführen sind." Leichenversuche und Tierexperimente hätten ihm ergeben, dals man die Umschnürung zweier Darmschlingen und des Mesenteriums der Verbindungsschlinge nur dann erreicht, wenn die Verbindungsschlinge äußerst kurz ist. 
Nehme man sie länger als $8 \mathrm{~cm}$, so gelinge die Abschnürung ihres Mesenteriums überhaupt nicht mehr, der Verlauf der Mesenterialgefäße bliebe dann immer unbeeinträchtigt.

Seiner Ansicht nach sei es durchaus fraglich, ob die von Jäckh festgestellte Gefäßthrombose im Mesenterium der Verbindungsschlinge bzw. die hämorrhagische Infarcierung, die Jäckh als Beweis für Einklemmung des Gekröses angesehen hatte, überhaupt eine primäre Veränderung sei.

Lauenstein hielt sie für sekundäre Erscheinungen, „die neben den Darmveränderungen einhergingen und die mit ihnen auf die gleichen noch aufzuklärenden, aber sicher in der Wirkung des Einklemmungsringes liegenden Ursachen zurückzuführen seien".

Dies war der Stand der Frage, als ich am 12. Juli 1907 an der Klinik Hofrat Hocheneggs folgenden Fall zu beobachten und zu operieren Gelegenheit hatte:

68 jähriger Taglöhner, seit Kindheit mit einem rechtsseitigen Leistenbruch behaftet, der im 20. Lebensjahr schon faustgrob war und immer größer wurde, da der Mann niemals ein Bruchband trug und trotzdem immer schwere Arbeit verrichtete. Reposition des Bruches gelang nie vollständig. Einige Male bestanden schon Brucheinklemmungen, die der Arzt alier immer leicht beheben konnte. Gestern Nachmittag traten wieder Einklemmungssymptome auf und da schonende Repositionsversuche nicht zum Ziele führten, wurde der Kranke seitens seines Arztes der Klinik überwiesen.

Status praesens: Es bestehen die Zeichen des Darmverschlusses. In der rechten Leiste eine mannskopfgroBe, kugelrunde, prall gespannte, tympanitisch schallende, von mächtigen Subkutanvenen überzogene Bruchgeschwulst. Dieselbe schließt sich medial ans Skrotum an, welches in seiner rechten Hälfte eine faustgroße, gleichfalls prall gespannte und tympanitisch schallende Bruchgeschwulst enthălt. Penisbaut zur Bedeckung der letzteren herangezogen. Der rechte Testikel nicht nachweisbar (auch der Kranke weiß über seine Lage keine Auskunft zu geben.) Die kopfgroße, außerhalb des Skrotums liegende und die skrotale Bruchgeschwulst sind voneinander durch eine tiefe Furche getrennt, kommunizieren aber, denn man kann die skrotale Bruchgeschwulst unter Quatschen verkleinern und fühlt dann in der anliegenclen Partie der großen Geschwulst deutlich den quatschenden, hinübergepreßten Darm. Die Hernie ist in der Gegend der Bruchpforte druckempfindlich. Abdomen mäßig stark meteoristisch, überall druckschmerzhaft. Im Unterbauch, median gelegen, mit ihrer Längsachse senkrecht gestellt, eine große, deutlich sich abkonturierende, keine Peristaltik oder Steifung zeigende, geblähte, hell tympanitisch schallende, also offenbar lokalmeteoristische Dünndarmschlinge, deren FuBpunkte nicht sicher nachweisbar sind, aber mit Wahrscheinlichkeit in die Gegend der Bruchpforte verlegt werden. 
Mit Rücksicht auf den geschilderten Befund stellte ich die Diagnose: Wahrscheinlich "retrograde Inkarzeration des Darmes", eventuell Dunndarmvolvulus oberhalb der Bruchpforte und schritt unverzüglich - etwa 20 Stunden nach Beginn der ersten Erscheinungen - zur Operation.

1)a ich das bisherige Geplänkel zwischen Lauenstein und seinen Gegnern schon mit Rücksicht auf meinen damals bereits publizierten Fall von Gekröseeinklemmung genau verfolgt hatte, ging ich mit dem gröliten Interesse an deu Eingriff. Ich wußte, daß es mir, richtige Diagnose vorausgesetzt, vergönnt sein könne, Feststellungen von prinzipieller Wichtigkeit zu machen - war doch $z$. B. noch in keinem Falle wälırend der Operation auf das wirkliche Verhalten des Mesenteriums der Verbindungsschlinge geachtet worden!

Meine Erwartungen wurden auch nicht getäuscht; der Operationsbefund war ein so außerordentlich schöner, daß ich schon damals an der Hand desselben gerne in die Diskussion eingetreten wäre. Aber ich war dazumal und die folgende Zeit mit anderen. noch dringenderen literarischen Arbeiten so sehr in Anspruch genommen, daß ich erst jetzt die Fäden wieder anspinnen konnte.

Doch zur Sache:

Ich machte einen Schrägschnitt an der Basis der Bruchgeschwulst, dem ich später der besseren Orientierung wegen einen Hilfsschnitt senkrecht darauf hinzufügte, der Bruchsack und Bruchhüllen weithin spaltete. Durchtrennung der Haut, des fascienartig verdichteten, subkutanen Bindegewebes, der Aponeurose des Obl. ext. und des Peritoneums, worauf eine mäßige Menge hämorrhagischen, leicht übelriechenden Bruchwassers abfließt. Es zeigt sich nun, daß in dem großen Bruchsack, der gegen das Skrotum eine divertikelartige Ausstalpung hat, zwei grobe Schlingenkonvolute liegen (Fig. 1):

1. Im medialen Abschnitt geblähter, zyanotischer, von einigen kleinen Petechien bedeckter Düundarm;

2. lateral davon, leer und normal ernährt, eine riesige Dickdarmschlinge, näılich das Cöcum, das Colon ascendens und ein großer Teil des Quercolon mit dem geschrumpften, am Bruchsack nach vorne zu breit und innig adbäreutem $\mathrm{Netz}^{1}$ ), ferner das untere, vielfach untereinander verwachsene Ileum. Dieses I)ünn-Dickdarmkonvolut hat ein Mesenterium commune, das Colon ascendens geht ins Quercolon ohne Flexurbildung über.

Aus der scharfrandigen, ovalen, etwa $7 \mathrm{~cm}$ langen, $4 \mathrm{~cm}$ breiten Bruchpforte ragen nur die beiden Schlingenkonvolute hervor, vom Mesenterium der Verbindungsschlinge ist nichts $z u$ sehen. Der zufuhrende Danndarm (bei a, Fig. 1) und der abführende Dickdarm (bei d, Fig. 1)

1) Der Bruchsack muß rings um diese breite Verwachsung umschnitten werden und in diesem Bereich bleibt ein handtellergroßes Stück Bruchsack auf dem später zu reponierenden Teil. 
lassen sich unschwer vorziehen, bei vorsichtigem Zug an b und c läßt sich auch ein bischen von den FuBpunkten der Verbindungsschlinge herausziehen, dieses Darmstück ist aber stark infarciert und ganz prall gespannt, so daß es auch nach Erweiterung der ohnehin weiten Bruclipforte sich nicht entwickeln läßt - es sei denn, man wollte brüske Gewalt anwenden.

Sofort nach Nachlassen des Zuges schlüpft die Verbindungsschlinge, deren Schenkel gleich von der Bruchpforte an divergieren, wierler in den Bauch zurück. Keines der vier Darmrohre zeigt auch nur die Spur einer Strangulationsfurche.

Ich widerstand der Lockung, die Bauchdecken von der Bruchpforte aus weithin zu spalten ${ }^{1}$, was natürlich die beste Aufklärung über das Verhalten desVerbindungsschlingenmesenterium gegeben hätte und zog es im Interesse radikaler Bruchheilung vor, eine Laparotomie an entfernter Stelle, über der Kuppe der Verbindungsschlinge, zu Hilfe zu nehmen, eröffnete also das Abdomen knapp links von der Medianlinie, durch die linke Rektusscheide hindurch, während ich den linken Musculus rectus (ähnlich wie bei dem von uns für die Appendektomie bevorzugten „Falltürschnitt") lateral wärts verzog.

Aus der Bauchhöhle entleert sich in großer Menge trübes, hämorrhagisches, übeiriechendes Transsudat (das schon früher in kleiner Menge selbst aus der noch nicht erweiterten Bruchpforte

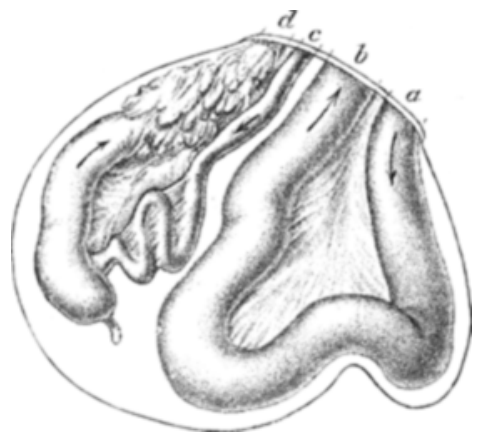

Fig. 1. Schematische Darstellung der Verhältnisse meines Falles nach Eröffnung und Spaltung des Bruchsackes.

abgesickert war) und nun läßt sich die vor der Operation als lokal mete-

1) Dies tat ich in einem späteren Fall, dessen Beschreibung ich im Anhang zu dieser Publikation bringe. 
oristisch geblähtes Darmstück palpatorisch und perkutorisch nachweisbar gewesene Verbindungsschlinge herausziehen - ein dunkelblaurotes, infarciertes, prall gespanntes Dünndarmkonvolut von mindestens $3 / 4 \mathrm{~m}$ Länge (Fig. 2).

Das Mesenterium der Verbindungsschlinge ist in der Nähe des Darmes ödematös und gleichfalls infarciert, die Infarcierung endigt, scheinbar ganz unmotiviert, ziemlich scharfrandig begrenzt, etwa handbreit vom Darmansatz.

Nun wird (Beckenhochlage), indem vom Bauch ber an den Schlingen gezogen und vom Bruch her reponiert wird, der ganze Bruchinhalt mühsam Schritt für Schritt zurückgebracht. Dabei ist es - wegen des bestehenden, das Repositionshindernis abgebenden Meteorismus der Bauchdärme - nötig, selbst einen Teil des Bruchinhaltes beim Bauchschnitt zu eventrieren, um nur allen Darm durch die Bruchpforte hineinzubringen.

Nach völliger Reposition zeigt sich, daB an der lateralen Bruchsackwand nahe der Bruchpforte ein haselnuBgroBer, schlaffer Körper hängt, der ektopische, atrophische Testikel. Umstechung des Samenstranges; linearer Verschiluß des großen Bruchsackhalses durch Peritonealnähte, Abtragung des überschüssigen Bruchsackes samt dem Testikel und des großen Hautbeutels.

Die Verbindungsschlinge hat sich mittlerweile etwas erholt, so daß ich sie als lebensfähig anspreche, um so mehr als die Serosa noch glatt ist und spiegelt. Sie wird daher samt dem übrigen, vor die Bauchwunde eventrierten Darm mübsam reponiert. Schichtenweise Naht des Bauchschnittes, schließlich VerschluB der Bruchpforte durch 8 Bassininähte, deren drei unterste den bloBgelegten Rektus mitfassen, bei ziemlich großer Spannung. Naht der Aponeurose, Hautnaht.

Der Verlauf war ein glatter. Am 27. VII. 1907 wurde der Patient geheilt in seine Heimat entlassen und unterm 10. III. 1909 gibt der dortige Arzt nach vorgenommener Nachuntersuchung die erfreuliche Auskunft, daß von einer Hernie keine Spur sei und daB der Mann trotz seines bohen Alters bei tadellosem Wohlbefinden seiner früheren, schweren Beschäftigung vollkommen nachgehe.

Durch diese meine Beobachtung ${ }^{1}$ ) war für mich der Beweis geliefert,

1. daß es tatsächlich, so wie Lauenstein es behauptet hatte, zu einer schweren Ernährungsstörung der Verbindungsschlinge kommen kann, ohne daß das Mesenterium derselben bis in die Bruchpforte hereinreicht,

2. daß lediglich die Starrheit der infarcierten Ver-

1) Einen zweiten, ganz ähnlichen Fall habe ich am 7. Sept. 1909, währead der Drucklegung der vorliegenden Arbeit, operiert. Ich bringe seine Beschreibung als Anhang zu dieser Publikation. 
Über das Wesen der sogenannten retrograden Inkarzeration des Darmes. 67

bindungsschlinge das Vorziehen derselben verwehrte, daß es also, im Gegensatz zu den Annahmen von Lauenstein, Haim u. a., nicht einmal einer vollkommenen Abschnürung der Fußpunkte der Verbindungsschlinge bedarf, um den rätselhaften Befund zu schaffen und

3. daß in der Tat, wie Haim schon behanptet hatte, das Zustandekommen des Befundes eine Inkarzeration der Bruchdarmschlingen und ihres Mesenterinms gar nicht zur notwendigen Voraussetzung hat und daß die Inkarzeration der Bruchdarmschlingen, wo sie bisher beobachtet worden ist, lediglich ein sekundärer oder wenigstens nebensächlicher Befund ist.

Tatsächlich findet sich in vielen von den bisher publizierten, für die Beurteilung der schwebenden Fragen heranzuziehenden Fällen die ausdrückliche Angabe, daß die Bruchdarmschlingen gar nicht oder nur wenig verändert waren, daß der zuführende Schenkel der höheren und der abführende der tieferen Bruchdarmschlinge sich unschwer entwickeln ließ usw.

Die Ansichten, die ich mir damals über die Ursachen der Zirkulationsstörung an der Verbindungsschlinge bildete und die sich mit meinen heutigen decken, werde ich unten noch ausführlicher entwickeln.

Hier muß ich zunächst auf die von mir bisher noch nicht erwähnte Theorie eingehen, welche Langer (11) schon 1903 zur Erklärung eines von ihm beobachteten Falles aufgestellt hat. Er stuitzt dieselbe auf die Tatsache, daß die Ernährungsgefäße des Darmes keineswegs überall senkrecht zur Längsachse des Organes an dieses herantreten, daß namentlich am Dickdarm und am unteren lleum „die Gefäße einfache aber weitläufige Bogen bilden, welche nahe am Darm liegen (Henle)". Es könne also die Verbindungsschlinge möglicherweise nur von beiden Seiten her, aber nicht direkt von der Gekrösewurzel aus ilır Blut zugeführt bekommen; bei einer derartigen Gefäßverteilung könnte es sich treffen, daß die von beiden Seiten her zur Verbindungsschlinge führenden Gefäße durch die Bruchpforte gemeinsam mit den Fußpunkten der Verbindungsschlinge stranguliert würden und daß die Ernährung der letzteren folglich leide, obwohl ihr zugehöriges Mesenterium intakt im Bauchraume liege.

Ich kann der erwähnten Art der Gefäßversorgung eine gewisse Bedeutung für das Zustandekommen von Ernährungsstörungen nicht 
absprechen und will nicht verschweigen, daß Langers interessante Theorie eine gewisse Stütze in einem einzig dastehenden Fall Pólyas (23) gefunden hat.

Hier lag das Cöcum und ein $6 \mathrm{~cm}$ langes Stück des untersten Ileum, also blob eine Darmschlinge im Bruchsack and zeigte nur geringe Einklemmungszeichen; hingegen waren die angrenzenden, im Bauche liegenden $25 \mathrm{~cm}$ des Dünndarmes nekrotisch, ihr Mesenterium hämorrhagisch infarciert; die orale Grenze der Veränderungen war verschwommen, die aborale, die mit der vorhandenen Schnürfurche am Ileum zusammenfiel, scharf.

Pólya legte diesen Befund, wie mir scheint, mit Recht, dahin aus, daß die Vasa ileocolica, welche ja das untere Ileum versorgen, durch den Bruchring mit abgeklemmt waren und daß bei dem Patienten, der an Myokarddegeneration und Endokarditis litt, die Herzkraft nicht ausreichte, um auf dem Wege der oberen Kollateralen der gefährdeten Darmpartie Hilfe zu bringen.

Bei der "retrograden Inkarzeration" kurzer Verbindungsschlingen könnte gelegentlich die Kompression dem Darm anliegender Gefäßbogen eine gewisse Rolle spielen, für die Ernährungsstörung langer Verbindungsschlingen hingegen (in Langers Fall betrug sie etwa $1 \mathrm{~m}$ ) erscheint es mir untunlich, diese Erklärung heranzuziehen.

War es nach meiner Beobachtung für mich erwiesen, daß es zu schwerer Ernährungsstörung an der Verbindungsschlinge kommen kann, obwohl ihr Mesenterium in der Bauchhöhle verblieb, so galt es für mich jetzt zu prüfen, ob nicht der umgekehrte, von Lauenstein hartnäckig geleugnete Modus, gegen den er sich in einer nochmaligen Publikation (16) wandte ${ }^{1}$ ), dennoch als zweite Type der "retrograden Inkarzeration" vorkommen könne.

Jäckh (6) hatte als Beweis für die Inkarzeration des Verbindungsschlingenmesenteriums durch die Bruchpforte angeführt, daß „das Mesenterium vom Darmansatz $a b$ in einer Breite von $4 \mathrm{~cm}$ (bei einer 60 bis $70 \mathrm{~cm}$ langen Verbindungsschlinge) ausgesprochen hämorrhagisch infarciert war" und daß „die Grenze gegen das gesunde Mesenterium durch eine scharfe, dem Darm parallel verlaufende Linie gebildet war, die nach beiden Seiten zu sich dem Darmansatz näherte und hier genau in die beiden Schnür-

1) In seiner neuesten, während der Drucklegung dieser Arbeit erschienenen Publikation (18) hat Lauenstein diesen Standpunkt aufgegeben, seit er selbst einen Fall beobachtet hat, bei dem tatsächlich das Mesenterium der Verbindungsschlinge in Bruchsack lag. 
Über das Wesen der sogenannten retrograden Inkarzeration des Darmes. 69

ringe überging. Jenseits der Schnürringe war am Mesenterium keine Spur von hämorrhagischer Veränderung mehr vorhanden".

Jäckh sah die scharfe Grenze der hämorrhagischen Infarcierung am Mesenterium als periphere Schnürfurche des doppelt abgeklemmten Mesenteriums an, eine Anschaung, die Lauenstein nicht gelten ließ. Ich kann Lauenstein nur beipflichten. Bei einer doppelten Einklemmung des Gekröses sind, wie mein schon erwähnter Fall (19) beweist, nicht nur an der peripheren Inkarzerationsstelle, sondern an der ganzen eingeklemmten Partie Veränderungen zu erwarten und auch nachzuweisen.

Ferner fand sich die gleiche scharfe Grenze der Infarcierung - ich werde auf sie noch zurückkommen - auch in meinem oben beschriebenen Fall, bei dem das Verbindungsschlingenmesenterium die Bauchhöhle gewils nicht verlassen hatte, und ebenso in meinem unten, im Anhang noch mitgeteilten Fall (Fig. 11).

Für die Fälle $J$ äckhs nehme ich in Übereinstimmung mit Lanenstein an, daß das Mesenterium der Verbindungsschlinge durch die Bruchpforte selbst nicht insultiert worden war. Wie steht es aber mit dem Falle, welcher Klauber den Anlaß geboten hatte, den doppelten Durchtritt des Mesenteriums der Verbindungsschlinge durch die Bruchpforte als Erklärungsgrund für die Zirkulationsstörung aufzustellen?

Bei der Herniotomie trat eine gutgefärbte Dünndarmschlinge von etwa $20 \mathrm{~cm}$ Länge hervor, dahinter eine zweite, etwas längere, mit der unteren nicht zusammenhängende ${ }^{1}$ ).

Die ca. $25 \mathrm{~cm}$ lange Verbindungsschlinge war dunkelblaurot, die Venen in ihrem Mesenterium thrombosiert, das Mesenterium selbst "ödematös verdickt."

„Alle drei Schlingen gehörten zu einem schmalen, langen Zipfel der Radix mesenterii, so daB bei der Resektion die Mesenterialabbindung in querer Richtung mit wenigen Ligaturen erfolgen konnte."

Ohne alle Argumente anerkennen zu können, die Klauber zu Hilfe nahm (10), um seine Ansicht gegen die Kinwände Lauensteins zu verteidigen, mul doch zugegeben werden, daß es tatsächlich in alten Brüchen lang herabhängende Dünndarmschlingen gibt, welche ganz aus der Fasson gekommen, deren Fußpunkte enorm genähert und nur durch ein ganz schmales Mesenterium miteinander verbunden sind; eine Form, die seit langem für das Zu-

1) Das „nicht zusammenhängend“ meinte Klauber offenbar nicht in bezug auf das Mesenterium, sondern so, daf das eine Darmrohr ins andere nicht überging. 
standekommen von Volvulus im Bruchsack oder in der Nähe der Bruchpforte verantwortlich gemacht wird.

Wenn eine derartige Schlinge, die lange im Bruchsack gelegen war, in die Bauchhöhle zurückgeschoben wird, so kann ich mir leicht vorstellen, daß es dazu kommen kann, daß z. B. bei einem Hustenstoß nicht die ganze Schlinge vorfällt, sondern daß ihre Kuppe in der Bauchhöhle zurückbleibt, und daß nur ihr Stiel, also ene Partie, an der das Mesenterium am schmälsten ist, in den Bruchsack hineintritt. Dann liegen zwei Darmstücke im Bruch-

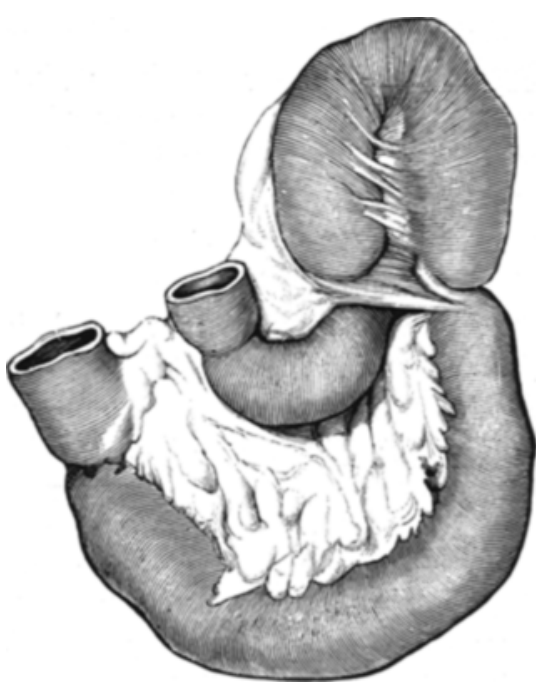

Fig. 3. Das durch Resektion gewonnene Präparat im Falle Hocheneggs. sack, verbunden durch eine im Bauch zurückgebliebene Schlinge, und bei der Schmalheit des die beiden Bruchdarmstücke verbindenden Mesenteriums ist wohl anzunehmen, daß es in toto mit vorfallen muß.

Ich finde also, daß die Erklärung Klaubers nicht ganz von der Hand zu weisen ist, obwohl ihm so wenig wie seinen Parteigängern $\mathrm{J} a ̈ c k h$ und $\mathrm{Haim}$ der Beweis für dieselbe gelang. In dem Falle H ocheneggs (5) scheinen die Verhältnisse auch derart gelegen zu haben, was mir namentlich aus der Abbildung des durch die Resektion gewonnenen Präparates (Fig. 3) hervorzugehen scheint ${ }^{1}$ ).

Es fanden sich im Bruchsack 1. ein geblähtes, tiefdunkelrotes Darmstück (die untere Schlinge in Fig. 3), 2. eine kollabierte, kürzere Schlinge, glatt, weniger dunkel; diese beiden Bruchdarmschlingen waren oberhalb des einklemmenden Ringes, innerhalb der freien Bauchhöhle, durch eine Darmschlinge verbunden, deren Schenkel durch ältere Adhäsionen miteinander verwachsen waren. Das ganze durch Resektion entfernte Konvolut $\mathrm{maB} 40 \mathrm{~cm}$.

Das durch die alten Adhäsionen verbundene Darmstück, die Kuppe der ganzen Schlinge, war doch offenbar früher einmal im

1) Dank dem liebenswürdigen Entgegenkommen der Verlagsbuchhandlung Urban \& Schwarzenberg bin ich in der Lage, das damalige Originalklischee zum Abdrucke zu bringen. 
C̈ber das Wesen der sogenannten retrograden Inkarzeration des Darmes. 71

Bruchsack drinnen gelegen; gerade die relative Starrlieit der Schlingenkuppe mag ihrem Wiedervorfallen einen gewissen Widerstand entgegengesetzt haben, sie wurde in der Nähe der Bruchpforte aufgehalten und es fielen statt ihr die beiden Schenkel des Schlingenstieles heraus, gemeinsam natürlich mit ihrem Mesenterium.

So möchte ich den Fall Hocheneggs deuten, ihn also zur Konstruierung eines $W$ ahrscheinlichkeitsbeweises dafür verwerten, daß tatsächlich eine Inkarzeration des Verbindungsschlingenmesenteriums im Sinne Klaubers vorkommen kann ${ }^{1}$ ).

Auch der erste, sehr gut beobachtete und wohl einwandsfreie Fall v. Wistinghausens (30) gehört hierher:

„Der Bruchinhalt wurde von 2 geblähten, bläulich rosa gefärbten Dünndarmschlingen gebildet, deren Aussehen auffallend mit dem des fraglos in Fäulnis befindlichen Bruchwassers kontrastierte. Sie waren, wenn auch nicht normal, so doch bedeutend weniger verändert als sich crwarten lieb. Das Auffallendste an dem vorliegenden Verhältnissen war aber, daB ler zu erwartende Vereinigungspunkt der beiden Darmschlingen im Bruchsack nicht zu finden war, so daß es den Anschein hatte, als wären durch die groBe Bruchpforte dieses alten Bruchsackes zwei Darmschlingen auf einmal vorgefallen.

Alle 4 Enden führten zur Bruchpforte zurück und rings um sie war der starr gespannte, äußere Leistenring zu fühlen. Dieser war vollständig vom hindurchtretenden Inhalt ausgefüllt. Nach Einkerbung des Ringes von außen gelang es, die medialen Wurzeln beider vorliegenden Schlingen vorzuziehen, die beide jenseits einer seichten Schnürfurche vollkommen normal waren.

Die lateralen Wurzeln folgten nicht auf Zug. Durch Untersuchung der Bruchpforte mit dem Finger lieb sich konstatieren, dap zwischen den medial und den lateral gelegenen Schlingen dicht oberhalb des Inkarzcrationsringes von hinten nach vorne eine scharfe Kanteverlief, die die Bruchpforte räumlich in zwei Teile teilte."

Diese Kante entpuppte sich als "das Mesocöcum, dessen unterer Rand als scharfe Kante gegen die Bruchpforte von außen unten nach oben vorne vorsprang, wobei seine Wurzel fast im Bereiche des Bruchsackes lag."

"Durch die mediale öfnung gelangte man in die freie Bauchhöhle, während die lateral von der genannten Kante gelegene Öfnung erst nach breiter Spaltung des Leistenkanales zugänglich wurde .... Nun konnte man den lateralen Teil der Schlinge vorziehen." Nach einer tiefen Schnürfurche folgte eine ca. $80 \mathrm{~cm}$ lange, ad maximum geblähte, schwer veränderte Schlinge, „so daß nun eine einzige groBe Darmschlinge vorlag, die folgende drei Charakteristilia zeigte:

1) Die beiden Publikationen Hellers $(3,4)$ habe ich leider erst während der Drucklegung meiner Arbeit kennen gelernt, kann sie daher nur mehr kurz berühren. Diese heiden Beobachtungen sind vollgiltige Beweise für das Vorkommen dieses Typus der sogenannten retrograden Inkarzeration, das übrigens ja auch nicht einmal mehr von Latenstein geleugnet wird (vergl, die Fußuote S. 71). 
1. zwei normale Partien an den beiden Enden aus der Bauchhöhle,

2. zwei leicht inkarzerierte aus dem Bruchsack und in der Mitte,

3. eine gangranöse Partie, aus der Bauchhöhle stammend."

Die große, geräumige Pforte des alten Skrotalbruches war also durch das in ihrem Niveal vorspringende, fixierte Cöcum und eine von diesem noch abgehobene Bauchfellfalte in zwei nebeneinander liegende Öfinungen geteilt. Durch die mediale war eine große Dünndarmschlinge herabgetreten, durch die laterale wieder in den Bauchraum hinaufgestiegen.

Bei diesem von v. Wistinghausen supponierten, ganz plausiblen Mechanismus mußte also die große Dünndarmschlinge mit ihrem ganzen Mesenterium durch die eine Lücke aus der Bauchhöhle in den Bruchsack, durch die zweite aus dem Bruchsack wieder in die Bauchhöhle zurückgekrochen sein - im Endeffekt also, wie in Hocheneggs Fall, wieder eine "retrograde Inkarzeration" ganz im Sinne Klaubers.

Der Zufall gab mir ferner Gelegenheit, am 3. Juni 1908 selbst einen Fall zu beobachten, bei dem das zweimalige Hindurchtreten des Mesenteriums durch die Bruchpforte als Ursache für die vorhandene Gangrän der Verbindungsschlinge durch die topographischanatomischen Verhältnisse über allen Zweifel erhoben wurde:

39 jährige, fettleibige Frau, die sich 1903 der Radikaloperation einer Nabelhernie unterzogen hatte, welche sehr bald rezidivierte. Nachdem schon längere Zeit Tag für Tag Kolikschmerzen aufgetreten waren, stellten sich anfangs Juli heftige Schmerzen ein. Dann trat unter starken Fieberbewegungen ein AbszeB auf, welcher Ende Juli 1909 spontan aufging.

Am 4. VIII. 1907 trat die Frau in meine Behandlung. Inmitten einer über faustgroßen Rezidivhernie bestand eine für den kleinen Finger durchgängige Fistel, aus der sich bald nach der Mahlzeit fast der ganze hohe Dünudarminhalt entleerte. Am 6. VIII. 1907 Operation (Sanatorium Loew). Die Fistel führt in die Mitte eines fest verbackenen, vollkommen unentwirrbaren Dünndarmkonvoluts von etwa $1 \mathrm{~m}$ Länge. Resektion des ganzen Konvoluts, zirkuläre Naht. Von einem radikalen Verschluß der Bruchpforte muB mit Rücksicht auf die nichts weniger als aseptischen Verhältnisse der Bauchdeckenwunde Abstand genommen werden. Heilung.

Am 2. VI. 1908 vormittags traten bei der Frau, die sich nach dem letzten Eingriff glänzend erholt und über $15 \mathrm{~kg}$ zugenommen hatte, plötzlich schwere Okklusionssymptome auf. Trotzdem wurde der Hausarzt erst 24 Stunden später berufen. Er fand eine kindsfaustgroße, inkarzerierte Rezidivhernie und da die Frau schon fäkulent erbrach, drang er auf sofortigen Transport nach Wien behufs Operation. Doch die Frau sträubte sich dagegen, so daß noch einige Stunden kostbarster Zeit verloren gingen. Als ich endlich abends an die Operation schreiten konnte, war der Zustand ein desolater. Die Fran bot das Bild des vorgeschrittenen, akutesten Darmverschlusses. Massenhaftes fäkulentes Erbrechen, Puls über 120, zeitweise 
aussetzend und so klein, daß ich die Gefahren der Narkose durch Lumbalanästhesie ( 0,07 Tropakokain) zu vermeiden suchte. Leider kam ich gerade damit aus dem Regen in die Traufe. Das Schicksal der armen Frau war ja wohl durch die vorgeschrittenen Veränderungen in der Bauchhöhle schon besiegelt, aber eine kurze Narkose hätte sie höchstwahrscheinlich doch ausgehalten.

Etwa 10 Minuten nach der Lumbaleinspritzung hingegen trat Somnolenz auf, die rasch in schweren Sopor überging, der Puls setzte aus, dann die Atmung und trotz Injektion von Exzitantien, trotz künstlicher Atmung usw. trat der Exitus eine halbe Stunde nach der Einspritzung ein ${ }^{1}$ ).

Durch diesen traurigen Zwischenfall wurde natürlich mein Eingriff unterbrochen, doch war ich so weit gekommen, um über den Befund volle Klarheit zu haben.

Nach Fröftinung des Bruchsackes flo 8 stinkendes Bruchwasser ab und es lagen zwei kurze, quer verlaufende, knapp aneinander gelagerte Darmstücke vor, beide gangränös, zusammen umrahmt von der fünfkronenstückgroßen Bruchpforte. Von ihrem Mesenterium war vorläufig nichts zu sehen. Nach Erweiterung der straffen Bruchpforte stürzte stinkendes, hämorrhagisches Bruchwasser en masse aus der Bauchhöhle heraus und ich konnte aus derselben die etwa $50 \mathrm{~cm}$ lange, dilatierte und trotz der schon vorgeschrittenen Diffusion noch ziemlich prall gespannte, vollkommen schwarze, mürbe Verbindungsschlinge herausziehen, die nach rechts hin gelagert war. Es zeigte sich, daß ein straffer, vertikaler Strang die Bruchpforte in zwei Hälften

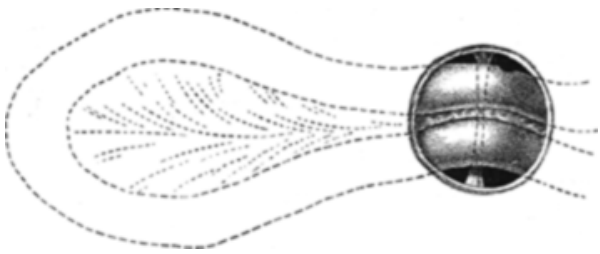

Fig. 4. Durch einen Strang ist die Bruablorte in zwei Teile geteilt; über diesen Strang ist eine Schlinge aus der Bauchhöhle in den Brnchsack and wieder zurück in die Bauchhöhle gekrochen. geteilt hatte. Über diesen Strang war die Darmschlinge, also natürlich zusammen mit ihrem Mesenterium, hinäbergeschlagen (siehe die schematische Darstellung der Verhältnisse, Fig. 4) und entsprechend den Rändern der Bruchpforte fanden sich am Darm vier tiefe Schnürfurchen.

Der Operationsbefund ist so klar, daß er kaum eines Kommentars bedarf.

Das Mesenterium einer „retrograd inkarzerierten“ Schlinge muß geradeso wie die beiden Bruchdarmstücke doppelt inkarzeriert gewesen sein, denn bei der Zweiteilung der Bruchpforte durch den sie überbrückenden Strang und seine festgestellte Lage zum Schlingenstiel ist etwas anderes gar nicht denkbar. Freilich gebe ich zu, daß gerade das Reiten der Schlinge auf dem Strang die Reinheit

1) Dasselbe Bild einer hyperakuten Vergiftung nach der Lumbaleinspritzung hatte ich schon früher einmal bei einem sehr dekrepiden, zur Amputation wegen Gangrän bestimmten Greis gesehen. Damals ging die Sache sogar so schnell, daß mit der Operation nicht einmal begonnen werden konnte. 
des Falles einigermaßen trübt. Aber das eine läßt sich aus dem Falle ableiten: wenn der Stiel einer etwa $50 \mathrm{~cm}$ langen Schlinge also die Fußteile ihres Darmrohres und das sie verbindende $\mathrm{Me}$ senterium, nach dem Hinüberkriechen über einen die Bruchpforte teilenden Strang in der Bruchpforte liegen und sich dort inkarzerieren können, weshalb sollte nicht gelegentlich der Stiel der Schlinge direkt in einen Bruchsack vorfallen können, so wie es Klauber sich dachte und wie ich es für Hocheneggs Fall annehme?

Einen ganz ähnlichen Fall wie den meinen hat später de Beule (1) beschrieben (Fig. 5).

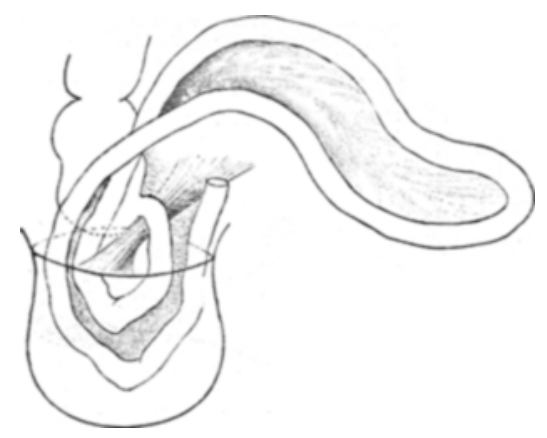

Fig. 5. Schematische Darstellung der Verhältuisse im Falle de Beules.

Die Pforte eines rechten Skrotalbruches war durch einen sie überbrückenden Strang in zwei Hälften geteilt, durch die mediale war das untere Ileum in Form einer großen Schlinge aus der Bauchhöhle in den Bruchsack herab- und durch die laterale war die Schlinge wieder ans dem Bruchsack in den Bauchraum hinaufgestiegen.

de Beule, der diese Form der "retrograden Inkarzeration" "Hernie en W secondaire" benennt, scheint mir für das Zıstandekommen derselben auf Taxisversuche, auf eine „falsche Reposition durch die zweite Hälfte der Lücke" zu viel Gewicht zu legen.

In meinem Falle ist ein Taxisversuch überhaupt nicht vorgenommen worden. Ich halte es für viel wahrscheinlicher, daß in solchen Fällen die Schlinge, noch solange sie frei ist, durch die eine Lücke hinein- und durch die andere wieder herauskriecht und nun erst, analog z. B. wie bei einer inneren Verknotung, die Sperrung der Darmpassage und der Blutzirkulation zustande kommt.

Kehren wir jetzt zu der ersten Form „retrograder Darminkarzeration" zurück, bei der also die Zirkulationsstörung in der Verbindungsschlinge erfolgt, ohne daß ihr Mesenterium mit in die Bruchpforte gerät, und sehen wir zu, wie sich das Rätsel der Zirkulationsstörung lösen läßt.

Lauenstein konnte anfangs keine auch nur einigermaßen befriedigende Antwort finden, weil er von der Voraussetzung ausging, daß das Mesenterium der Verbindungsschlinge ungeknickt, gerade- 
wegs von der Radix mesenterii bis zum Darmansatz verlaufe. Es ist Lanensteins Verdienst, später selbst (16) darauf hingewiesen zu haben, daß aber von einem derartigen geraden Verlauf des $\mathrm{Me}-$ senteriums gar keine Rede sein könne. Lauenstein war zur Ansicht gekommen, daß sehr wohl eine "Zugspannung" auf das Mesenterium der Verbindungsschlinge einwirken könne. Er nahm dabei an, daß die Fußpunkte der Verbindungsschlinge beiderseits durclı den Bruchring abgeschnürt seien. Ich lasse iln selbst sprechen:

„Die kollaterale Gefäßversorgung hört an beiden Seiten auf, (lie Peristaltik arbeitet vergeblich oder gar nicht, der Lymphstrom wird gehemmt, der Inhalt stagniert, und, während die Fußpunkte der Schlinge festgehalten werden, kann das im Bruchringe festgeklemmte Mesenterium der beiden äußeren Schlingen eine andauernde Zugspannung auf das im Leibe liegende Mesenterium der Verbindungsschlinge ausüben."

Lauenstein stellte die Verhältnisse seiner vier klinischen Beobachtungen an der Leiche her und das schien ihm durchaus geeignet, seine eben geäußerten Überlegungen zu stützen.

„Durch den Zug nämlich, den das Mesenterium der beiden äußeren Schlingen auf das Mesenterium der Verbindungsschlinge ausübt, bildet sich an diesem ein arkadenförmig markierter Bogen, der wie ein scharfer Rand genau so zu der Verbindungsschlinge angeordnet ist wie z. B. die scharfe Linie der Mesenterialveränderung im Jäckhschen Falle. Bei einer Länge der beiden äußeren Schlingen von je $15 \mathrm{~cm}$, der inneren von $80 \mathrm{~cm}$ und einer Höhe des Mesenteriums von $14 \frac{1}{2} \mathrm{~cm}$ bildete sich an dem Mesenterium der Verbindungsschlinge ein arkadenförmiger, scharfer "Zngrand“, dessen entfalteter Bogen, konvex nach der Radix zu gerichtet, $8 \mathrm{~cm}$ von dieser entfernt war. Peripher von dieser "Zugarkade" eigentlich müßte man unter Berücksichtigung der Lage während der Einklemmung "Zugring" sagen - war das Mesenterium der Verbindungsschlinge, also in $6 \frac{1}{2} \mathrm{~cm}$ Entfernung von ihrer höchsten Höhe, schlaff und frei von Zugwirkungen. Darnach muß man annehmen, dals der zentrale Abschnitt des Mesenteriums der inneren Schlinge einer Spannung unterliegen kann, die je stärker desto unheilvoller auf die Ernährung des Darmes wirken und sich den nachteiligen Folgen der doppelten Abschnürung des Darmrohres selbst summieren muß."

Fs ist ein Leichtes, sich an der Leiche von dem Anftreten der"Zugarkade" an dem Mesenterium der Verbindungsschlinge zu über 
zeugen, wenn man zwei nicht unmittelbar benachbarte Dünndarmschlingen aneinanderbringt und sie, bzw. deren Mesenterium, nun kräftig nach abwärts zieht.

Es ist weiterhin überraschend, wie genau diese Zugarkade mit der von Jäckh beschriebenen bogenförmigen Grenze der hämorrhagischen Infarcierung am Verbindungsschlingengekröse seines ersten Falles übereinstimmt. Und eine ganz ähnliche Grenze der Mesenterialveränderungen hat schon Schmidt (26) beschrieben, was keiner der späteren Bearbeiter des Themas beachtet zu haben scheint. Ich bringe nebenstehend (Fig. 6) eine Kopie einer Originalskizze Schmidts und dessen die Abbildung erläuternde Worte:

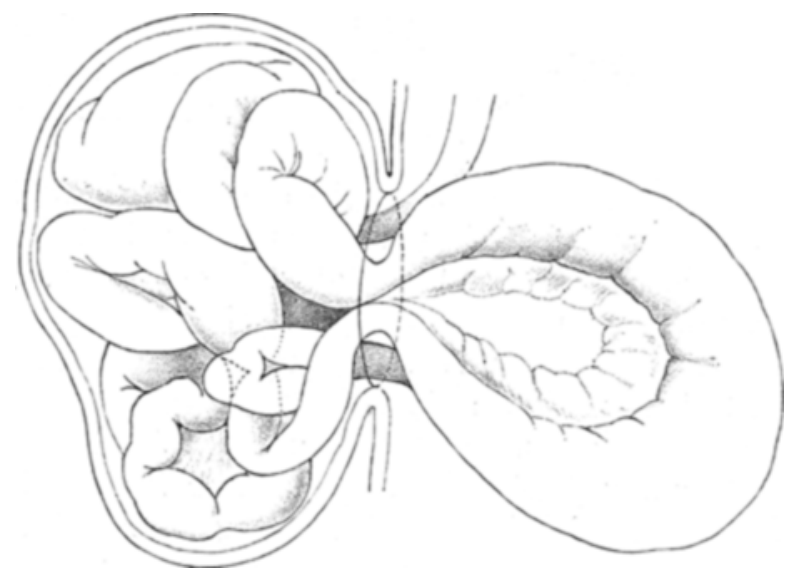

Fig. 6. Beobachtung Sehmidts.

„Das groBe Netz trat am oberen Umfang der Bruchpforte in den Bruch ein. Hinter ihm verliefen zwei Darmrobre, ein zuführendes und ein abführendes, durch die Bruchpforte, frei, nicht abgeschnürt. AuBerdem aber ragte am rechten oberen Umfang der Bruchpforte eine ca. $60 \mathrm{~cm}$ lange Darmschlinge aus dem Bruche nach dem Bauche hinein. Dieselbe befand sich im Zustand höchster Spannung und venöser Stase. Sie war tief blauschwarz, glänzend, nicht trübe noch mürbe.

Die der konkaven Seite des Darmrohres angrenzende Zone des Mesenterium, wie sie in der Figur angedeutet ist, war gleichfalls dunkelblaurot. Jenseits dieser Zonewar das Mesenterium blässer und bläulichrot".

Ganz ähnlich verhielt sich die Grenze der Mesenterialveränderungen in zwei Fällen Lauensteins, ferner in meinen einschlägigen Fällen, und schließlich ist auf die schönen Beobachtungen de Beules (1) und Neumanns (22) großes Gewicht zu legen; 
de Beule sowohl als Neumann haben in je einem Fall von der Bruchpforte aus eine ausgiebige Herniolaparotomie vorgenommen und so sich die Verbindungsschlinge mit ilhrem Mesenterium noch in situ zur Ansicht gebracht. Dasselbe konnte ich in dem während der Drucklegung dieser Zeilen von mir operierten Falle tun, dessen Beschreibung ich unten noch als Anhang bringe.

De Beule stieß anf eine $25 \mathrm{~cm}$ lange, noch lebensfähige, aber in ihrer Ernährung doch schon gestörte Verbindungsschlinge mit Blutunterlaufungen in der angrenzenden Mesenterialpartie. Das zugehörige Mesenterium bildete eine nach oben zu konvexe Arkade, deren Rand recht scharf gespannt war. Neumann traf das Mesenterium der Verbindungsschlinge "straff ausgespannt zwischen dem Scheitel der Verbindungsschlinge und den beiden Fußpunkten derselben. Zwischen diesen Fußpunkten beschrieb die Umschlagstelle des Mesenteriums der Verbindungsschlinge einen straffen, nach unten konkaven Bogen".

Für mich besteht kein Zweifel, dals die im Leichenversuch sich regelmäßig bildende Arkade auch in vivo beim Mechanismus der sog. retrograden Inkarzeration eine Rolle spielt, wenn auch de Beule auf Grund seiner nicht vollkommen einwandfreien Tierversuche das Urteil fällte, daß der "Zugarkade“ Lauensteins keine nennenswerte Bedeutung beizumessen sei.

de Benle kam zu der Anschauung, daß der Inhalt der beiden Bruchsackschlingen im Moment ihres Vorfallens zum größten Teil in die Verbindungsschlinge ausgestreift werde und so den Anstoß zur Überdehnung gebe, welche für sich allein schon die Ernährungsstörung der Verbindungsschlinge erkläre.

Damit entfernt sich meiner Meinung nach de Beule von der richtigen Deutung des ganzen Zustandes, geradeso wie Lauenstein (17), der, de Beules Arbeit besprechend, besonders hervorhebt, daß seiner Ansicht nach "die "Zugarkade" des Mesenteriums allein schwerlich die Ernährung der Darmwand gefährdet, daß vielmehr die Abschnürung der Darmwand hierfür unerläßliche Vorbedingung sein dürfte".

Daß die Stagnation und Zersetzung des Inhalts einer vollen Darmschlinge, die an ihren beiden Enden abgeschnürt worden war, mit der ihr folgenden Überdehnung der Darmwand ohne irgendwelche gleichzeitige Alteration der Mesenterialgefäße eine Ernährungsstörung der überdehnten Darmpartie zur Folge haben muß, ist unbestreitbare Tatsache. Aber diese Überdelınung für sich allein erklärt keineswegs die ausgedehnte Infarcierung des zugehörigen 
Mesenteriums und vor allem die scharfe Abgrenzung der infarcierten Zone, wie sie so oft in den einschlägigen Fällen beobachtet worden ist.

Wenn ich nunmehr den Versuch unternehme, die komplizierten Verhältnisse so zu erklären, wie ich sie mir zurechtgelegt habe, so will ich nur das Wesentliche hervorheben und dementsprechend auf eine Fülle von Details, die im Einzelfall als prädisponierende Momente imponieren könuen, gar nicht eingehen oder sie höchstens streifen.

Mein Erklärungsversuch setzt in jenem Momente an, wo bereits zwei nicht unmittelbar benachbarte Darmschlingen in den Bruchsack eingetreten und dort durch irgendwelche Kräfte festgehalten sind.

Dabei braucht man keineswegs gleich an eine Inkarzeration der beiden Schlingen zu denken, es genügt vollkommen, wenn z. B. durch einen aus ganz nebensächlichen Gründen entstandenen Meteorismus die beiden Darmschlingen veranlaßt wurden, nach dem Bruchsack auszuweichen. Eine gewisse prädisponierende Rolle kann vielleicht der Zufall spielen, daß als zweite Schlinge nicht jene, die sonst immer den Bruchsack beschickte, sondern eine höher gelegene mit etwas kürzerem Mesenterium herausgepreßt wurde; damit würde die Tatsache übereinstimmen, daB mehrfach in den Operationsbeschreibungen von Veränderungen an der Verbindungsschlinge und an ihrem Mesenterium die Rede ist, welche gar keinen Zweifel zulassen, daß gerade die Verbindungsschlinge früher einmal im Bruchsack gelegen war.

Nehmen wir also an, zwei Darmschlingen, verbunden durch ein im Bauch zurückgebliebenes, mehr minder langes Verbindungsstück, lägen nebeneinander im Bruchsack und seien hier festgehalten; das Mesenterium der Verbindungsschlinge liegt frei im Bauchraum. Es braucht nun gar kein starker Zug an den Mesenterien der Bruchdarmschlingen sich geltend zu machen, um die "Arkade" am Verbindungsschlingenmesenterium herzustellen, wie sie Lauenstein im Leichenversuch und de Beule am Lebenden beobachtet haben.

Der Zug am Mesenterium der Bruchdarmschlingen muß aber anch die dazwischen liegende, annähernd dreieckige Strecke jenes Teiles des Verbindungsschlingenmesenteriums, das von der Radix mesenterii bis zum Rand der Arkade sich ausbreitet, nach abwärts ziehen. Das Mesenterium der Verbindungsschlinge bekommt so in der gespannten Arkade gewissermaßen eine neue Haftlinie, und wenn nun die Verbindungsschlinge infolge der in ihr zunehmenden Blähung sich exzentrisch ansdehnt, so muß die Mesenterialstrecke zwischen Arkadenrand und Darmansatz nach der entgegengesetzten Rich- 
Über das Wesen der sogenanuten retrograden Inkarzeration des Darmes. 79

tung wie die Mesenterialstrecke zwischen Radix und Arkade sich ansspannen. Die Folge wird unter allen Umständen eine spitzwinkelige Abknickung des Verbindungsschlingenmesenteriums gerade an der Lauensteinschen Arkade sein, und das führt naturgemäß anch zu einer intensiven Abknickung der Mesenterialgefäße, was venöse Stase, hämorrhagische Infarcierung, Zunahme des lokalen Meteorismus bis zu den höchsten Graden, und in ihrer letzten Konsequenz Gangrän der ganzen Verbindungsschlinge bewirken muls.

Bleibt noch zu erklären, was denn eine stärkere Blähung der Verbindungsschlinge, einen lokalen Meteorismus in ihr hervorruft. In einzelnen Fällen mag sie schon von Haus aus so viel enthalten, daß sie sich gleich nach dem Vorfallen ihrer beiden Nachbarschlingen in dem oben angedeuteten sinne exzentrisch ausbreitet; es kann vielleicht auch während des Vorfallens der Nachbarschlingen ein Teil des Inhalts dieser sich gegen die Verbindungsschlinge entleeren (de Beule) und so die Spannung in ihr vermehren; unter allen Umständen jedoch das wichtigste Moment ist die Kompression der beiden Fußpunkte der Verbindungsschlinge durch die Bruchpforte, und wenn nur einmal zu dieser noch die venöse Stase hinzukam, dann wird bald durch das Zusammenwirken aller Faktoren der Lokalmeteorismus immense Grade erreichen, was wieder die Absperrung der Mesenterialgefäße an der Arkade noch verschärfen muß.

Schon der erste meiner Leichenversuche, die ich zur Klärung der Frage unternahm, hat mich von der Richtigkeit meiner hier entwickelten Anschanungen überzeugt.

Ich ging bei meinen Versuchen folgendermaßen vor: Ausgiebiger Luängsschnitt am äußeren Rektusrand bis in den änßeren Leistenring hinein. Beim unteren Wundwinkel werden zwei hier gut herauszubringende Dünndarmschlingen lerausgezogen. Die Fußpunkte der Verbindungsschlinge werden durch eine Naht aneinandergeheftet und durch die gleiche Naht am äußeren Leistenring fixiert. Damit ist die Lauenstein sche Arkade -- eigentlich ein ovalär gestalteter Schlitz mit unterer Spitze - hergestellt. Das Mesenterium der Verbindungsschlinge von der Arkade bis zum Darmansatz liegt schlaft da.

Nun wird durch eine an einer der beiden Bruchdarmschlingen angelegte Lücke ein Kautschukrohr bis in die Verbindungsschlinge eingeführt; die beiden Fulspnnkte der Verbindungsschlinge werden - der eine natürlich über das eingeführte Rohr linweg - ganz 
locker abgebunden. Wenn man nun die Verbindungsschlinge - um die Vorgänge an ihr und ihrem Mesenterium besser beobachten zu können, empfiehlt es sich, sie vor die Bauchwunde zu lagern durch das Rohr aufbläst, so bläht sie sich und spannt die Mesenterialplatte von der Arkade bis zum Darmansatz, so daß sie in ihrer Gestalt an einen Fächer erinnert (Fig. 8). Das ganze System ist jetzt so starr, daß man die Verbindungsschlinge nicht mehr nach abwärts umlegen kann, und die Gefäße erleiden am Rand der Arkade

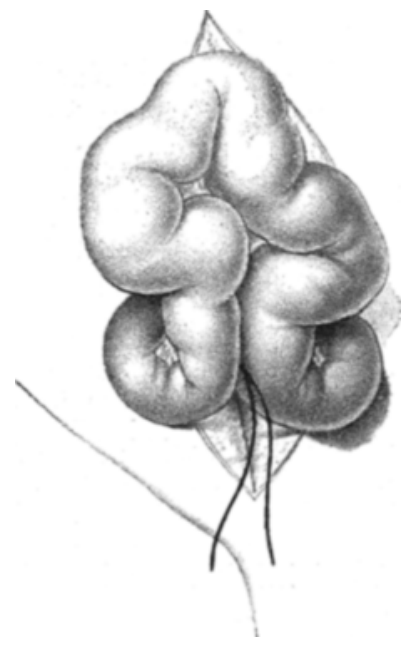

Fig. 7. Die Faßpunkte der Verbindungs- Fig. 8. Dieselbe Schlinge wie nebenan, an ihren schlinge sind in der Höhe des âuBeren FuBpankten abgeschnürt and ad maximum gebläht. Leistenringes fixiert; die Schlinge ist Man sieht die schlitzförmige "Zugarkade", die noch wenig gefüllt und daher geschlängelt. Mesenterialplatte zwischen ihr und dem Darmrand ist vollkommen ausgespant.

eine spitzwinkelige Abknickung. Besser wie jede Beschreibung erläutern die nebenstehenden, nach der Natur angefertigten Zeichnungen (Fig. 7-9 und die schematische Fig. 10) den Vorgang.

Ich habe den Versuch des öfteren gemacht und kam immer zu demselben, den wahren Mechanismus dieser Type der sog. retrograden Inkarzeration so sinnfällig demonstrierenden Ergebnis, daß ich damit die Frage in ihren wesentlichen Punkten für gelöst halte ${ }^{1}$ ).

1) In der Erwartung, im Tierexperiment eine weitere Stütze za finden, versuchte ich, analoge Verhältnisse wie am menschlichen Kadaver an einer Katze 
Über das Wesen der sogenannten retrograden Inkarzeration des Darmes. 81

Die schwere Ernährungsstörung der Verbindungsschlinge und die oft genug schon an dem wiederentfalteten Mesenterium beobachtete scharfe Begrenzung der hämorrhagischen Infarcierung mit einem dem Darmansatz annähernd parallelen Bogen finden so ungezwungen ihre Erklärung (vgl. die Figuren 9 u. 11).
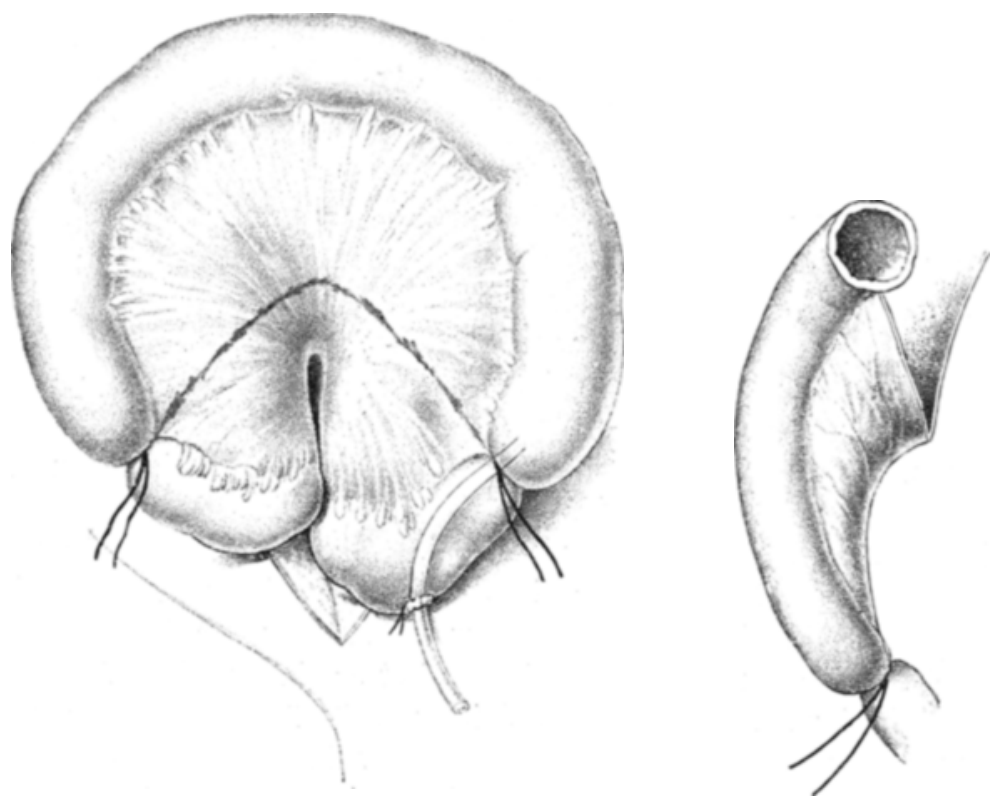

Fig. 9. Dasselbe Objekt wie Fig. 8. Der scharfe Rand der Fig. 10. Sebematischer Längs"Zugarkade" wurde mit Tinte beschmiert, daraufhin worde sehnitt durch das Objekt der die Naht, welche die beiden Fußpunkte der Verbindungs- Fig. 8. Man beachte die scharfschlinge aneinander und an den äuBeren Leistenring fixierte, winkelige Abknickang der Medurchtrennt, die Schlinge und ibr Mesenterinm weiter heransgezogen. Man beachte, wie der Tintenstrich genan der von senterialplatte. Jäekh a. a. hervorgebobenen Grenze der Mesenterialveränderungen entspricht $u$. vergleiche dieses Bild mit Fig. 11.

und an einem Kaninchen herzustellen. Die Mesenterialverhältnisse dieser Tiere sind jedoch von denen am Menschen so außerordentlich verschieden; daß ich beide Male gleich anfangs zur Überzeugung gelangte, meine Bemühungen seien anssichtslos. An dem dünnen, langen, fast jeder Kräuselung entbehrenden Mesenterium läßt sich wohl auch eine Art „Zugarkade" erzeugen, aber die Mesenterialstrecke von der Radix mesenterii bis zum Arkadenrand bleibt schlaff, und selbst wenn man die abgeschnürte Verbindungsschlinge ad maximum aufbläst, gelingt es nicht, diesen Mesenterialteil zur Spannung zu bringen, die B]utzirkulation bleibt unbehindert. Die beiden Versuche überzeugten mich derart von der Aussichtslosigkeit, die „retrograde Darminkarzeration“ am Tier, wenigstens an den beiden genannten Tiergattungen $z \mathbf{a}$ jmitieren, daß ich beide Male die schon vorgenommene Abschnürung wieder löste und den Versuch abbrach. 
$\mathrm{Da} B$ oberhalb der lokalmeteoristischen, infarcierten Verbindungsschlinge Meteorismus auftreten muß, daß unter der Einwirkung desselben die nächsthöhere, im Bruchsack liegende Schlinge sich bläht und infolge dieser Volumszunahme samt ihrem Mesenterium und samt der zweiten, leeren Bruchdarmschlinge in einer nicht allzu geräumigen Bruchpforte leicht ins Gedränge kommen kann, so daß gelegentlich zum Schluß anch eine Inkarzeration beider Bruchdarmschlingen mit vier Strangulationsfurchen vorliegt, ist leicht verständlich. Aber, ich wiederhole es nochmals, die Inkarzeration der Bruchdarmschlingen ist dort, wo sie überhaupt zustande kommt, etwas durchaus Sekundäres und nicht etwa ein die Ernährungsstörung der Verbindungsschlinge auslösendes Moment.

Auch die bedeutende Weite der Bruchpforte, die von fast allen Beobachtern hervorgehoben wurde, steht mit der „retrograden Inkarzeration" nur insofern in einem kausalen Znsammenhang, als sie das Vorfallen von mehr als einer Darmschlinge begünstigt.

In nebensächlichen Punkten sind ungezählte Variationen noch denkbar; so möchte ich hier der Befunde Manningers (20) und Takayasus (29) Erwähnung tun, die beide in ihren Fällen die zweite, höhere Bruchdarmschlinge nicht mit ihrem Mesenterium, sondern bloß in Form eines Darmwandbruchs vorgefallen fanden.

So wie ich den Zustand auffasse, hat er eine gewisse Verwandtschaft mit dem, was Wilms "Wringverschluß des Darms" nennt und was Rokitansky seinerzeit als ,Volvulus des Darms um seine Längsachse" registriert hatte; nur daß bei der "retograden Inkarzeration" die Umbiegung des Mesenteriums allein noch keine Verlegung des Darmlumens bedingt. 'Tatsächlich hat schon Jäckh (6) die Frage aufgeworfen, ob nicht vielleicht durch eine vorhandene Drehung des Mesenteriums eine scharfwinkelige Abknickung der Mesenterialgefäße zustande kommen könne, und auch Laroyenne(12) hat in dem von ihm publizierten Fall daran gedacht, ob nicht etwa eine Drehung der Verbindungsschlinge um ihre Achse mit Schuld an der Gangrän gewesen ist.

Eine Drehung der Verbindungsschlinge um die Mesenterialachse, also ein Volvulus einer Darmschlinge in unmittelbarer Nähe der Bruchpforte, während die nächsthöhere und die nächsttiefere Darmschlinge in den Bruchsack hineinhängen, müßte natürlich ein der sog. retrograden Inkarzeration sehr ähnliches Bild liefern.

Als ein derartiger Volvulus muß der durch Obduktion festgestellte Fall Sultans (28) aufgefaßt werden, bei dem sich, wie Sultan selbst hervorhebt, die Schenkel der gangränösen Verbin- 
dungsschlinge kurz vor ihrem Eintritt in die Bruchpforte kreuzten; ich gehe daher auf diesen Fall nicht näher ein.

Es lassen sich also drei verschiedene Typen der sog. retrograden Darminkarzeration unterscheiden.

Die erste (iruppe bilden jene Fälle, bei denen die Verbindungsschlinge nekrotisiert, obwohl ihr Mesenterium durch die Bruchpforte in keiner Weise bedrückt wird; die Verbindungsschlinge leidet in ihrer Lirnährung. weil das Mesenterium und die darin verlaufenden Gefäße innerhalb der Bauchhöhle eine spitzwinkelige Abknickung ganz besonderer Art erleiden.

In die zweite Gruppe gehören die scheinbar noch selteneren Fälle, bei denen das Mesenterium der Verbindungsschlinge zweimal durch die Bruchpforte zieht und dadurch abgeknickt wird.

Die dritte 'I'y pe wird durch den einzig dastehenden Fall Pólyas repräsentiert, in dem die Abschnürung der Vasa ileocolica und des untersten Ileum nahe am Cöcum genügte, um ein Stück des anschließenden. oberhalb des inkarzerierenden Ringes gelegenen Ileum zu' Gangrän zu bringen, weil bei dem an schweren Gefäßveränderungen leidenden Kranken die Anastomoseubahnen nicht ausreichten. um von oben her dew in seiner Ernährung bedrohten Darmabschnitt Hilfe zu bringen.

Für die zweite und dritte Type paßt der Name retrograde Inkarzeration angesichts der Definition. die Maydl diesem Begriff gegeben. Für die weitaus häufigeren Fälle der ersten Gruppe ist die Bezeichnung "retrograde Darninkarzeration" hingegen ebenso unangebracht wie der von Lanenstein gebrauchte Ausdruck „zwei Darmschlingen im eingeklemmten Bruch"; denn es handelt sich weder un eine retrograde Inkarzeration, noch braucht es sich um eine echte Brucheinklemmmg zu handeln. Aber es wird schwer halten, eine wirklich prägnante, nicht zu langatmige Bezeichnung für den Zustanıl zu finden.

Vielleicht ließe sich für die Fülle der zweiten und dritten Type die Bezeichnung ,echte retrograde Darminkarzeration“, für jene der ersten Gruppe hingegen der Name „falsche retrograde Darminkarzeration" einbürgern.

An hall g.

Nach Abschluls der vorliegenden Arbeit, während ihrer Drucklegung, spielte mir der Zufall noch einen einschlägigen Kasus in die Hände, den ich seiner Wichtigkeit wegen hier noch einfügen möchte. 
51 jährige Bäuerin, seit 12 Jahren mit einem linksseitigen Leistenbruch behaftet, der allmählich bis über Kindskopfgröße erreichte, niemals aber irgendwie nennenswerte Beschwerden verursachte. Am Abend des 6. IX. 1909 stellten sich plötzlich schwere Okklusionssymptome ein, während der Bruch sich nicht mehr zurückbringen lieb. Der Zustand verschlechterte sich rapid and da Taxisversuche, durch den in der Nacht berufenen Arzt vorgenommen, zu keinem Ziel führten, wurde die Frau am Vormittag des 7. September nach Wien an die Klinik geschafft.

Status praesens: Die kräftig gebaute, etwas fettleibige Frau bietet alle Zeichen des akuten Darmverschlusses. Sie ist schwer kollabiert, der Puls ist sehr klein, 120, es besteht starke Cyanose.

Die bis zur Mitte des Oberschenkels herabreichende, also ungewöhnlich große linksseitige Labialhernie ist ziemlich stark gespannt, schallt tympanitisch.

Das mäBig stark meteoristische Abdomen zeigt deutliche Asymmetrie: Das linke Hypogastrium ist deutlich vorgewölbt und dieser Vorwölbung entsprechend tastet man eine groBe, prall gespannte, hochtympanitisch klingende, offenbar lokal-meteoristische Darmschlinge.

In Anbetracht dieses Befundes läßt sich eine gewöhnliche Brucheinklemmung unschwer von der Hand weisen. Die Diagnose schwankt zwischen, falscher retrograder Inkarzeration desDarmes" und zwischen Volvulus einer Darmschlinge oberhalb des Bruchsacks, doch neige ich mehr zu der ersten Annahme, da ich vermute, daß beim Volvulus oberhalb einer Bruchpforte der Bruch weniger gespannt wäre.

Nach einer intravenösen Digaleninjektion schreite ich unverzüglich zur Operation in oberflächlicher Äthernarkose.

Schnitt parallel zum Poupartschen Band über die Basis der Bruchgeschwulst. Nach Eröffnung des Bruchsacks entleert sich hämorrhagisches, leicht übelriechendes Bruchwasser und es lassen sich nun zwei Schlingenkonvolute herausziehen. Das mediale, annähernd $110 \mathrm{~cm}$ lange, ist nur mäßig gebläht und zeigt, ebenso wie das zugehörige Mesenterium, außer Cyanose keine nennenswerte Veränderung. Die laterale, etwa $90 \mathrm{~cm}$ lange Schlinge hingegen ist stark gebläht, prall gespannt, blaurot und ihr Mesenterium zeigt unscharf begrenzte fleckige hämorrhagische Infarkte.

Die Serosa beider Bruchdarmschlingen ist überall noch glatt und $\mathrm{g}$ änzend.

Die vier Schenkel der beiden Bruchdarmschlingen füllen die geräumige Bruchpforte nicht völlig aus, denn man kann noch ohne Gewalt einen Finger neben den Darmschlingen durch die Bruchpforte einführen. Von einer Brucheinklemmung im strengen Sinne des Wortes kann also keine Rede sein.

Dementsprechend lassen sich auch alle vier Schlingenschenkel aus dem Bauch etwas vorziehen, dabei zeigt sich, daß die vorderen Schlingenschenkel in die Verbindungsschlinge übergehen. Vom Mesenterium der Verbindungsschlinge ist im Bruchsack nichts zu sehen.

Ich eröffne nunmehr die Bauchböhle am äußeren Rand des linken Musc. rectus. Es flieBt eine ziemlich reichliche Menge hämorrhagischen, 
übelriechenden Transsudates ab und vor uns liegt die überdehnte, düsterblaurote, prall gespannte, aber noch spiegelnde Verbindungsschlinge. Ihr Mesenterium ist schwer infarciert, dick und plump, und dabei a usgespannt wie ein $\mathrm{Fächer.}$

Ich verlängere nunmehr den Bauchschnitt nach abwärts bis in die Nähe des äuBeren Leistenringes und kann so den Zusehern, genau wie ich es erwartet hatte, die "Arkade" im Mesenterium der Verbindungsschlinge und die spitzwinklige Abknickung des Mesenteriums entlang der Arkade demonstrieren. Die Verhältnisse liegen genau so wie in Fig. 8 u. 10.

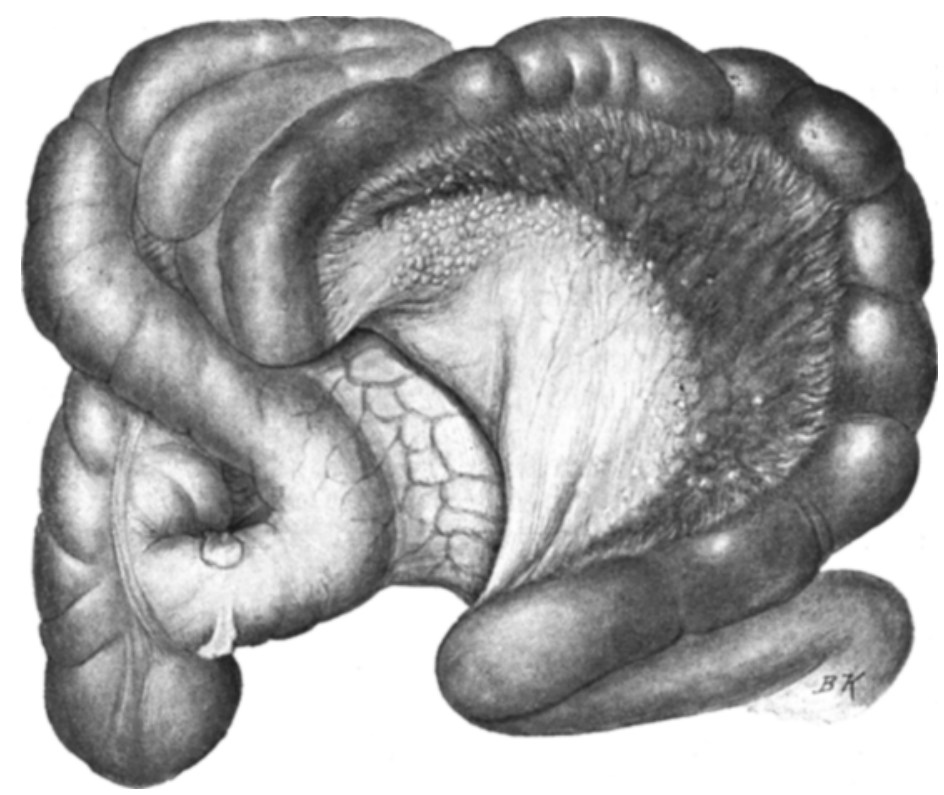

Fig. 11. Das durch die Obduktion gewonnene Präparat. Die Verbindungsschlinge und ihr Mesenterium ist angebreitet, man sieht die charakteristische, scharfe Grenze der Infarzierang.

Um völlig klaren Einblick in die Verhältnisse zu bekommen, spalte ich schlieBlich noch die Bruchpforte selbst und kann so demonstrieren, daB die beiden Fubpunkte der "Arkade" gerade in der Höhe der Bruchpforte liegen. Von den vier die Bruchpforte passierenden Darmrohren zeigt nur eines - die Stelle, an der die Verbindungsschlinge in die mediale Bruchdarmschlinge übergeht - eine halbzirkuläre, anämische Schnürfurche.

Die Verbindungsschlinge mißt $80 \mathrm{~cm}$. Nach Spaltung der Bruchpforte läBt sich das Mesenterium der Verbindungsschlinge vollends entfalten und es bietet sich uns nun der äuberst instruktive Anblick, wie die hämorrhagische Infarcierung und Verdickung des Mesenterium fast mit einer haarscharfen Linie entsprechend der "Arkade" absetzt (Fig. 11). Es zeigt sich, daB die mediale Bruchdarmschlinge vom untersten Ileum gebildet wird, die Valvula Bauhini liegt nur wenige 
Zentimeter von der Bruchpforte entfernt. Der Zustand der Kranken hat sich einstweilen so verschlechtert -- der Radialpuls ist nicht mehr fühlbar - daB jeder weitere Versuch, sie zu retten, vergeblich erscheint. Ich begnüge mich daher mit der Reposition der Darmschlingen und schließe die Bauchböhle durch Naht. - Nachmittags schwere Meläna, zunehmender Verfall. $6^{1 / 2}$ Stunden post operationem Exitus. -

Aus dem Obduktionsbefund (Prof. Dr. Stoerk) sei folgendes hervorgehoben:, $7 \mathrm{~cm}$ über der Bauhinschen Klappe beginnt die Veränderung des unteren Ileumabschnittes, gekennzeichnet durch eine mäBige Erweiterung des Darmrohres und Hyperämie der Serosa. In gleicher Beschaffenheit erstreckt sich die Ileumveränderung $123 \mathrm{~cm}$ nach aufwärts, bis zu einer durch eine halbzirkuläre, blasse, $1 / 2 \mathrm{~cm}$ breite Marke gezeichneten Stelle. Von hier an erscheint der Dünndarm $81 \mathrm{~cm}$ weit noch stärker gedehnt, seine Wand schwarzrötlich verfärbt; in diesem Bereich weist das zugehörige Gekröse in seiner ganzen Dicke eine sehr ausgeprägte hämorrhagische Infarcierung auf, die mit einem radixwärts konkaven, flachen Bogen plötzlich absetzt (Fig. 11).

Die hämorrhagische Infarcierung dieses Gekröseabschnittes mißt an hrer breitesten Stelle $9 \mathrm{~cm}$, während ihr Rand an diesem Punkt $26 \mathrm{~cm}$ von der Gekrösewurzel entfernt ist, die Gesamtlänge des Mesenteriums hier demnach $35 \mathrm{~cm}$ beträgt.

Weiter nach aufwärts zeigt der Dünndarm eine minder starke, allmählich abnehmende Hyperämie seiner Wand und entsprechend dem untersten Abschnitt dieser Darmpartie ist das zugehörige Gekröse in einer Längserstreckung von etwa $20 \mathrm{~cm}$ von fleckweise gruppierten, unscharf begrenzten, nahe dem Darmansatz liegenden Blutungen durchsetzt .... Adipositas cordis, Fettinfiltration der Leber."

Dem Gesagten brauche ich wohl nichts mehr hinzuzufügen.

Einen besseren Beweis für die Richtigkeit meiner Anschauungen konnte ich mir gar nicht wünschen!

In seiner neuesten, während des Drucks meiner Arbeit erschienenen Publikation spricht Lauenstein (18) die Meinung aus, „daß schon jetzt der Zeitpunkt da ist, um mit Hilfe der durch die bisherige Kasuistik gelieferten Anhaltspunkte den aussichtsreichen Versuch zu machen, die, Hernie en $W^{\prime}$ schon vor der Operation zu diagnostizieren". Dieser Ansicht muß ich vollkommen beipflichten; Beweis dafür, daß auch mir in meinen beiden Fällen die Wahrscheinlichkeitsdiagnose unschwer gelang.

Ich bin absichtlich auf die diagnostische Seite der in Rede stehenden Affektion nicht ausführlich eingegangen, glaube aber bei der Beschreibung meiner Fälle genügend hervorgehoben zu haben, was mich zur Diagnose führte: gleich Lauenstein halte ich die Tatsache, daß ein großer Bruch vorliegt, gemeinsam mit dem Nachweis einer lokalmeteoristischen Schlinge oberhalb der Bruchpforte, die sogar eine deutliche Vorwölbung, eine deutliche 
Asymmetrie des Bauches bedingen kann, für genügend, um mit großer Wahrscheinlichkeit den in Rede stehenden Zustand zu diagnostizieren. Differentialdiagnostisch kommt daneben in erster Linie der Volvulus einer Darmschlinge in der Nähe einer Bruchpforte in Betracht, in dessen Folge der meteoristische Darm oberhalb der gedrehten Schlinge gegen den Bruchsack ausweicht. In solchen Fällen dürfte der Bruchsack aber doch weniger prall gespannt sein als bei der sog. retrograden Inkarzeration.

\section{Literaturverzeichnis.}

1. de Beule, F., La hernie étranglée en $W$ avec étranglement rétrograde de l'intestin. Bull. de l'académie royale de méd. de Belg. 1908, S. 545.

2. Haim, E., Über retrograde Darminkarzeration. Zentralbl. f. Chir. 1906, S. 950 .

3. Heller, E., Zur Kenntnis der retrograden Darminkarzeration. Med. Klinik 1908, S. 151.

4. Derselbe, Weiterer Beitrag zur Kenntnis der retrograden Darminkarzeration. Med. Klinik 1908, S. 1268.

5. Hoch en e gg,J., Jahresbericht der I. chirurg. Klinik des Hofrates Prof. Albert in Wien, Schuljahr 1887. Wien u. Leipzig, Urban \& Schwarzenberg, 1889, S. 98.

0. Jäckl, A., Über retrograde Inkarzeration des Darmes. Deutsche Zeitschr. f. Chir., Bd. 87, S. 536.

7. Jenckel, A., Zur Frage der retrograden Inkarzeration des Darmes. Zentralbl. f. Chir. 1907, S. 1057.

8. Dersclbe, Atresia acquisita intestini. Deutsche Zeitschr. f. Chir., Bd. 90, S. 330 .

9. Klauber, O., Zwei Dünndarmschlingen im eingeklemmten Bruch. Deutsche med. Wochenschr. 1906, S. 145.

10. Derselbe, Die Gangrän der retrograd inkarzerierten Darmschlinge. Zentralbl. f. Chir. $190 \bar{i}$, S. 1027.

11. Langer, A., Über retrograde Inkarzeration des Darmes. Wiener klin. Wochenschr. 1903, S. 475 .

12. Laroyenne, L., Hernie compliquée d'étranglement rétrograde de l'intestin. Gaz. des hôp. 1907, Nr. 24.

13. Lauenstein, C., Über eine seltene Form der Einklemmung des Dünndarmes im Leistenbruch. Verh. der D. Ges. f. Chir. 1894, II., S. 250.

14. Derselbe, Zwei Dünndarmschlingen im eingeklemmten Bruch. Deutsche Zeitschr. f. Chir., Bd. 77, S. 581.

15. Derselbe, Zur Frage der Entstehung der Gangrän der Verbindungsschlinge der ,zwei Darmschlingen im eingeklemmten Bruch“. Zentralbl. f. Chir. 1907, S. 713.

16. Derselbe, Die Ernährungsstörung der Verbindungsschlinge. Zentralbl. f. Chir. 1907, S. 1198.

17. Derselbe, Referate einschlägiger Publikationen. Zentralbl. f. Chir. 1908, S. 1512 . 
88 LoRenz, Über d. Wesen d. sogen. retrograden Inkarzeration des Darmes.

18. La uenstei $n$, C., Ist es möglich, die „zwei Darmschlingen im eingeklemmten Bruch" zu diagnostizieren? Zugleich ein nener Beitrag zu der Pathologie der "Hernie en W“ resp. der "retrograden Darminkarzeration“. Deutsche Zeitschr. f. Chir., Bd. 100, S. 155.

19. Lorenz, H., Einklemmung von Dünndarmgekröse in einer Spalte des großen Netzes. Deutsche Zeitschr. f. Chir., Bd. 86, S. 260.

20. Manninger, V., Über retrograde Darminkarzeration. Zentralbl. f. Chir. 1906, S. 1064.

21. Maydl, K., Über retrograde Inkarzeration der Tuba und des Processus vermiformis in Leisten- und Schenkelhernien. Wiener klin. Rundschau 1895, Nr. 2.

22. Neumann, A., Zur Pathologie der sogenannten retrograden Inkarzeration. Deutsche Zeitschr. f. Chir., Bd. 91, S. 433.

23. Polya, E. A., Beiträge zur Kenntnis der retrograden Inkarzeration. Wiener klin. Rundschau 1906, S. 101.

24. Derselbe, Inkarzeration zweier Dünndarmschlingen in einem Bruchsacke. Wiener klin. Rundschau 1907, Nr. 3.

25. Pringle, Some cases of hernia in which several loops of bowel were strangulated in the same sac. Edinburgh med. journ. 1906, S. 513.

26. Schmidt, B., Eigentümliches Zustandekommen einer Darmeinklemmung bei einem großen Nabelbruch. Zentralbl. f. Chir. 1880, S. 513.

27. Siebert, K., Über retrograde Inkarzeration des Darmes. Inaug.-Diss. Königsberg i. Pr. 1907.

28. Sultan, G., Über den Mechanismus der retrograden Darminkarzeration. Zentralbl. f. Chir. 1907, S. 1518.

29. T a ka y a s u, M., Über die sogenannte „retrograde Inkarzeration des Darmes“. Deutsche Zeitschr. f. Chir., Bd. 96, S. 504.

30. v. Wistinghausen, Zur Kasuistik der retrograden Inkarzeration. Arch. f. klin. Chir., Bd. 68, S. 419 . 